\title{
Identification of Cyanobacteria Inhabiting Paddy Fields in Intermediate Zone and Dry Zone of Sri Lanka
}

\author{
R.P.U.I. Amarawansa, B.L.W.K. Balasooriya ${ }^{1}$ *, W.S. Dandeniya ${ }^{2}$, \\ B. Suganthan ${ }^{3}$ and T. Dasanyaka ${ }^{1}$ \\ Postgraduate Institute of Agriculture \\ University of Peradeniya \\ Sri Lanka
}

\begin{abstract}
Cyanobacteria have the ability to fix atmospheric nitrogen to plant available forms; thus, useful in producing bio-fertilizers especially for rice cultivation. In this study, cyanobacteria were isolated from soil samples collected from 23 paddy fields in Kurunegala, Matale, Anuradhapura and Polonnaruwa Districts under IL1, IM3, DL1b and DL1c agro ecological regions, respectively. Soil $\mathrm{pH}, E C$, active $C$ and exchangeable $K$ contents varied considerably among soils from four regions. Culturable cyanobacteria were isolated using Blue Green medium ( $p H 7$ ) and thirteen isolates were tentatively identified based on morphological characteristics. Oscillatoria was the most common cyanobacteria among sampling sites in IL1, IM3 and DL1c agro ecological regions. Microsystis was the most prevalent unicellular group in ILI and DL1c agro ecological regions. In DL1b, unicellular Aphanocapsa was commonly found followed by filamentous Pseudanabaena and Oscillatoria. From this research thirteen axenic cultures were established for further studies. The diversity of cyanobacteria was high in the regions with high diversity of paddy cultivated environments.
\end{abstract}

Keywords: Paddy, biofertilizer, Cyanobacteria, $\mathrm{N}_{2}$ fixation

\section{INTRODUCTION}

Cyanobacteria thrive in favourable growth conditions in fresh water and wetland ecosystems including lowland paddy fields, which are manmade wetland ecosystems. They live as freeliving organisms (e.g. Aphanocapsa, Gloeocapsa and Merismopedia) and in symbiotic associations (e.g. Anabaena sp. with Azolla) (Kulasooriya, 2011). Cyanobacteria are a morphologically diverse group. They can be grouped into uni-cells (e.g. Synechocystis), colonies of individual cells (e.g. Aphanothece), unbranched filaments (e.g. Lyngbya), aggregations of multiple filaments in a common sheath (e.g. Microcoleus), false-branched forms (e.g. Scytonema) and true branched forms (e.g. Stygonema), and those forming baeocytes (endospores) (e.g. Myxosarcina) or forming exospores (e.g. Chamaesiphon) (Wehr and Sheath, 2002). Cyanobacteria are major nitrogen $\left(\mathrm{N}_{2}\right)$ fixing prokaryotic organisms in the paddy field water and the uppermost soil layer (Roger, 1996). Their diversity in the rice paddies and nitrogen supplying potentials vary according to the growth stage of the rice plant

\footnotetext{
1 Department of Biotechnology, Faculty of Agriculture and Plantation Management, Wayamba University of Sri Lanka, Sri Lanka

2 Department of Soil Science, Faculty of Agriculture, University of Peradeniya, Sri Lanka

3 School of Chemical, Materials and Biomedical Engineering, College of Engineering, University of Georgia, USA

* Corresponding author: wajira.Balasooriya@wyb.ac.lk)
} 
and physico-chemical environment of the paddy soil (Prasanna et al., 2009; Song et al., 2005).

Cyanobacteria have been used in formulations of biofertilizers especially for rice cultivation (Kulasooriya and Magana-Arachchi, 2016). In addition to $\mathrm{N}_{2}$ fixation, cyanobacteria stabilize soil surface and increase water holding capacity. Some cyanobacteria excrete plant growth promoting substances such as growth hormones, vitamins, amino acids, and organic acids, and suppress weed growth, increase available phosphorous level in soil and decrease the effects from soil salinity (Saadatnia and Riahi, 2009). Soil pore structure is improved by filamentous growth and secretion of adhesive substances. Endosymbiosis of some cyanobacteria with aquatic flora (e.g. Azolla), (Kneip et al., 2008) found to be more successful in fixing nitrogen compared to free-living cyanobacteria. Azolla are widely used in China, certain parts in Philippines and Vietnam as a fertilizer (Kulasooriya, 2011).

Less colonization of the introduced environment during field application is a limiting factor for developing and popularizing biofertilizers or inoculants based on cyanobacteria (Naveed et al., 2015). This can be due to failed acclimatization to prevailing geochemistry or competition and predation by native soil micro flora and micro-fauna (Kulasooriya and Magana-Arachchi, 2016). Isolating cyanobacterial species from local paddy fields is an essential initial step in developing biofertilizers as these microorganisms are well adapted to prevailing soil environmental conditions. Thus, the aim of the current study was to develop a culture collection of cyanobacterial isolates from paddy fields at intermediate and dry zones of Sri Lanka. The descriptive results on the morphological identification of cyanobacterial isolates and their distribution among different locations are presented in this paper.

\section{METHODOLOGY}

\section{Sampling and sampling sites}

Soil samples were collected from 23 paddy fields in Kurunegala $(n=7)$, Matale $(n=4)$, Anuradhapura $(n=5)$ and Polonnaruwa $(n=5)$ under IL1, IM3, DL1b, and DL1c agroecological regions respectively (Figure 1). The soils in the four locations belong to Batalagoda series (Typic Endoaquents), Matale series (Typic Rhodudalfs), Hurathgama series (Typic Endoaqualfs) and Kuda Oya series (Typic Endoaqualfs), respectively (Mapa $e t$ al., 2005 and 2010). Paddy fields under rain-fed and major and minor irrigation were used whenever available for sampling to obtain high diversity in culture collection. After georeferencing the sampling site, 3 sub samples were collected from the surface soil layer $(0-10$ $\mathrm{cm})$ to make a composite sample per field and immediately transported to the laboratory on ice and stored in $4{ }^{\circ} \mathrm{C}$ until analyses. 


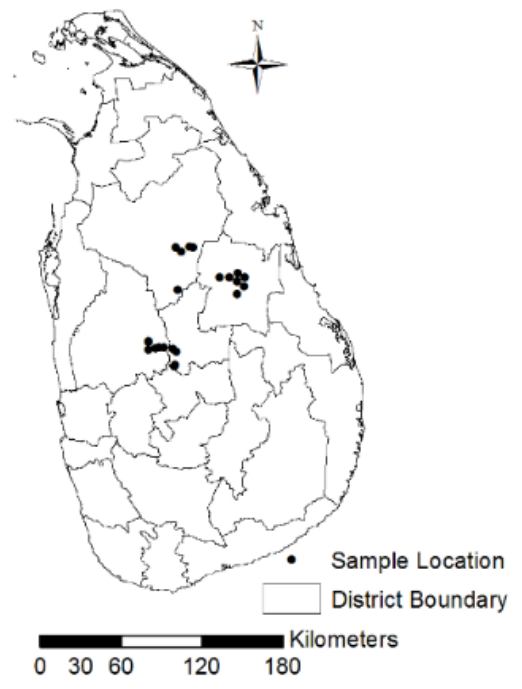

Figure 1. Distribution of sampling sites

\section{Soil analyses}

Each sample was analyzed for moisture factor (MF), electrical conductivity (EC) and soil $\mathrm{pH}$ (1:5 soil: water). Soil active $\mathrm{C}$ content was analysed by Permanganate Oxidizable C (POXC) technique (Culman et al., 2012) and exchangeable $\mathrm{K}$ of soil samples were measured using Ammonium acetate method (Lathiff, 2007a).

\section{Sample preparation and isolation of cyanobacteria}

Sub samples of soils $(10 \mathrm{~g})$ were thawed and mixed with $90 \mathrm{ml}$ autoclaved deionised water and the soil suspension was allowed to settle for 10 minutes. Prepared soil suspension was filtered using Whatman No. 1 filter paper and the filter paper with filter cake was transferred to a flask with $200 \mathrm{ml}$ of Blue Green medium with nitrogen (BG 11, pH 7.5) (Meeks, 2017). Liquid cultures were kept on shaker at $100 \mathrm{rpm}$ and $2000 \mathrm{~lx}$ light conditions $(16 / 8 \mathrm{~h})$ at 28 ${ }^{\circ} \mathrm{C}$. After two weeks of culturing a dilution series was prepared to determine the optimum dilution of the culture for inoculation on solid media (1\% bacteriological agar) using spread plate method. Plates were incubated in replicates at $28{ }^{\circ} \mathrm{C}$ and illuminated with fluorescent light (2000 lx) (16/8 h).

\section{Identification of culturable Cyanobacterial species by morphological observations}

A light microscope fitted with a digital camera was used for the morphological identification, and images were captured at 40, 100 and $400 \times$ magnification. Identification of different species/genotypes of culturable cyanobacteria was performed based on the keys developed by Wehr and Sheath (2002). Morphologically identified cyanobacterial species were further purified by streaking on solid medium until an axenic culture was obtained. Axenic liquid cultures were prepared by transferring single colonies from axenic solid cultures to $5 \mathrm{ml}$ of BG 11 liquid medium. 


\section{RESULTS AND DISCUSSION}

Cyanobacteria are ubiquitous as they have a great adaptability to environmental variations. Paddy field ecosystem facilitates suitable environmental conditions including light, temperature, water and nutrient availability for the growth and the establishment of cyanobacteria (Kondo and Yasuda, 2003). Thus cyanobacteria are highly abundant in paddy soils. In soil ecosystem, cyanobacteria are important players in fixing nitrogen, stabilizing the soil surface, increasing water holding capacity and promoting plant growth via secretion of plant growth promoting substances. Factors including dry/wet season, soil $\mathrm{pH}$, available $\mathrm{P}$ and $\mathrm{N}$ fertilizer input are found to affect the growth of cyanobacteria in paddy soils (Roger, 1996). Medium $\mathrm{pH}$ is a very important factor for the growth and establishment and the diversity of cyanobacteria. Most suitable $\mathrm{pH}$ has generally been reported to range from neutral to slightly alkaline for their growth (Kaushik, 1994). In culture media, the optimal pH ranges from 7.5 to 10 with a lower limit of 6.5 to 7.0.

In the present study, soil samples were collected from 23 locations and soil physico-chemical properties varied considerably among these locations (Table 1). Soil $\mathrm{pH}$ ranged from neutral to slightly acidic. Higher EC values were observed in paddy soils from Anuradhapura and Pollonnaruwa Districts than from Matale and Kurunegala. Observed values for soil $\mathrm{pH}$ and EC across the four districts were within the favourable range for paddy cultivation (less than $0.15 \mathrm{dS} / \mathrm{m}$ of EC, 6-7 of soil $\mathrm{pH}$ ), while exchangeable $\mathrm{K}$ was slightly lower than the optimum range (80-160 $\mathrm{mg} \mathrm{K} / \mathrm{kg}$ ) in sampling sites in Anuradhapura and Polonnaruwa (Lathiff, 2007b). These variations in soil parameters could be resulted due to edaphic factors, climatic factors and physiographic factors of crops. Also it could lead to harbour diverse groups of microorganisms.

Table 1. Moisture content, $\mathbf{p H}, \mathbf{E C}$, active $\mathrm{C}$ and exchangeable $\mathrm{K}$ (mean \pm standard deviation) of soils collected from paddy fields in Kurunegala, Matale, Anuradhapura and Polonnaruwa under IL1, IM3, DL1b and DL1c agro ecological regions, respectively.

\begin{tabular}{lccccc}
\hline District & $\begin{array}{c}\text { Moisture } \\
\text { Factor }\end{array}$ & pH & $\begin{array}{c}\text { EC } \\
\mathbf{d S} / \mathbf{m}\end{array}$ & $\begin{array}{c}\text { Active C } \\
(\mathbf{p p m})\end{array}$ & $\begin{array}{c}\text { Exchangeable } \\
\text { K (ppm) }\end{array}$ \\
\hline IM3 (n=4) & $1.64 \pm 0.19$ & $6.68 \pm 0.26$ & $0.012 \pm 0.002$ & $568 \pm 283$ & $90 \pm 20$ \\
IL1 (n=7) & $1.55 \pm 0.15$ & $6.83 \pm 0.18$ & $0.018 \pm 0.013$ & $771 \pm 322$ & $97 \pm 32$ \\
DL1b (n=5) & $1.52 \pm 0.19$ & $6.82 \pm 0.54$ & $0.075 \pm 0.043$ & $1111 \pm 501$ & $72 \pm 39$ \\
DL1c (n=7) & $1.71 \pm 0.18$ & $6.61 \pm 0.13$ & $0.037 \pm 0.022$ & $1479 \pm 319$ & $64 \pm 32$ \\
\hline
\end{tabular}

A total of 80 isolates were made collectively from all locations and these were assigned to 13 genera tentatively based on morphology. The isolates included 6 unicellular (Chroococcus, Aphanocapsa, Aphanothece, Synechococcus, Johannesbaptistia, and Microsystis) (Figure 2) and 7 filamentous (Lyngbya, Oscillatoria, Leptolyngbya, Pseudanabaena, Anabaena, Spirulina and Nostoc) (Figure 3) cyanobacteria. 


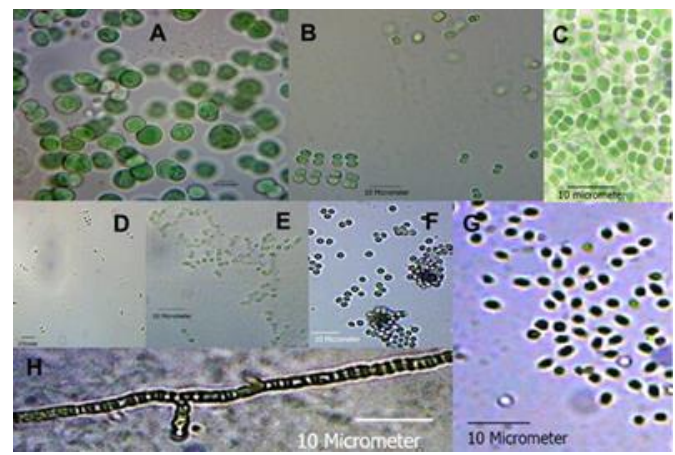

Figure 2. Unicellular cyanobacteria (A, B, and C) Chroococcus, (D) Aphanothece, (E) Synechococcus, (F) Aphanocapsa, (G) Microsystis, (H) Johannesbaptistia

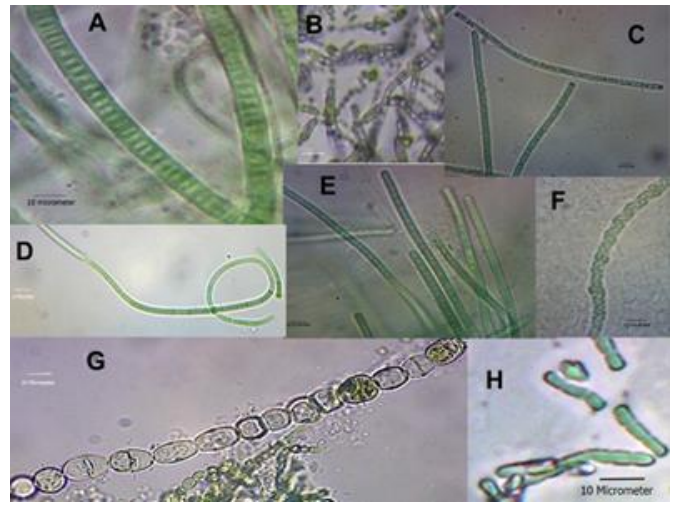

Figure 3. Filamentous cyanobacteria (A and E) Oscillatoria, (B) Anabaena, (C) Leptolyngbya, (D) Lyngbya, (F) Spirulina, (G) Nostoc and (H) Pseudanabaena

The prevalence of different types of cyanobacteria in the four regions is shown in Figure 4. Filamentous Oscillatoria was the most common cyanobacteria among sampling sites in IL1, IM3 and DL1c agro ecological regions; whereas, in DL1b region unicellular Aphanocapsa were more commonly found followed by filamentous Pseudanabaena and Oscillatoria. Microcystis was the most prevalent unicellular group in IL1 and DL1c regions. Several unicells i.e. Synechococcus, Aphanothece and Johannes baptistia and filamentous types i.e Anabaena, Lyngbya and Spirulina were found only in paddy fields from Kurunegala district under IL1 agro ecological region indicating high diversity of cyanobacteria. The occurrence of different genera based on morphological classification is in the order of Kurunegala > Anuradhapura > Polonnarua > Matale. This was expected because the diversity of paddy growing environments among sampling sites in Kurunegala was higher than other three regions. Sampling sites in Kurunegala represented rice cultivated under rain-fed, minor and major irrigation schemes which leads to different cropping systems (rice-rice, rice-other filed crop and rice-fallow). Whereas, sampling sites in Anuradhapura and Polonnaruwa were under major or minor irrigation schemes and those in Matale were rain-fed paddy fields. 


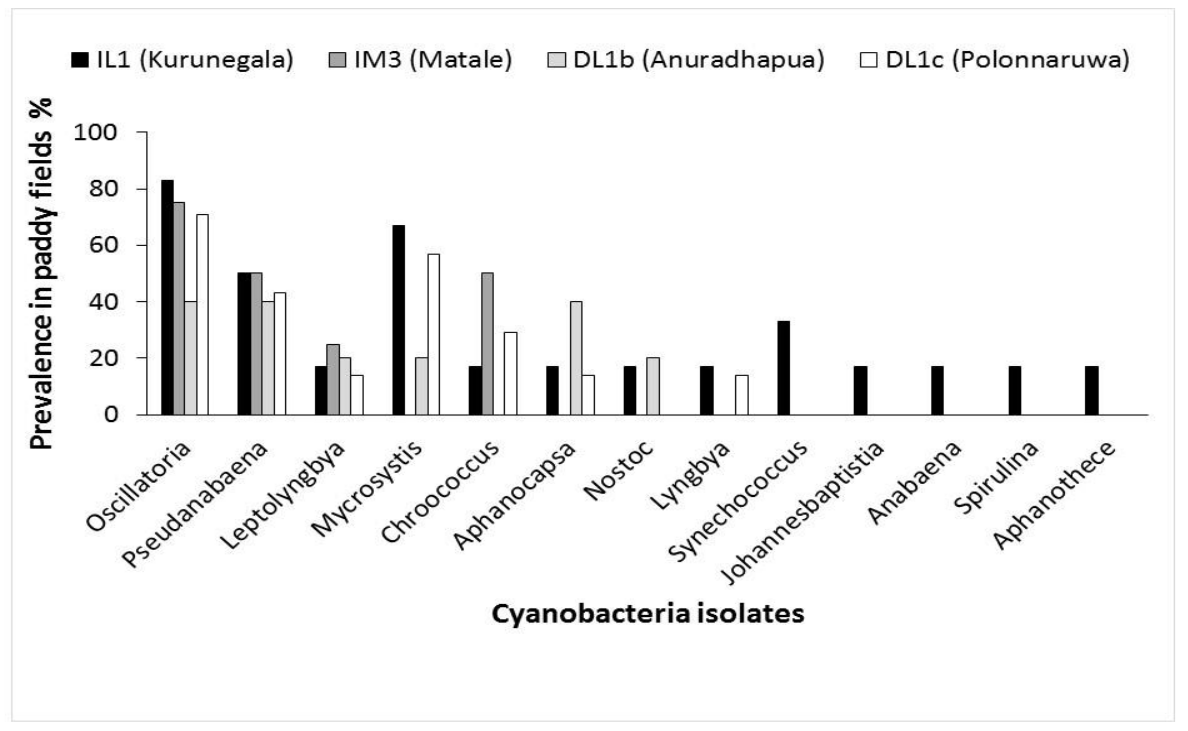

Figure 4. Prevalence of different cyanobacteria among sampling sites fall under the IL1, IM3, DL1b and DL1c agro ecological regions in Kurunegala, Matale, Anuradharpura and Polonnaruwa Districts respectively.

Cyanobacteria are found as a prominent group in rice soil microbial community (Kulasooriya and Maganarachchi, 2016). A recent study by Wanigatunge et al. (2014) has reported the cyanobacterial diversity in paddy fields and other wetland ecosystems including freshwater and brackish water in Sri Lanka using morphological and molecular identification. They found that Genus Microcystis, Gleocapsa, Gloeothece, Leptolyngbya, Phormidium, Plectonema, Pseudanabaena, Anabaena and Calothrix representing three cyanobacterial Orders namely, Chroococcales, Oscillatoriales and Nostocales, were prominent in paddy soils at Gampola, Elpitiya, and Thotagamuwa located in the Wet zone (Wanigatunge et al., 2014). In the current study 13 tentatively identified cyanobacterial genera representing six cyanobacterial Orders (IL1, IM3, DL1b and DL1c) were found. The difference in prevalence could be partly due to the diversity of rice growing environments and related favourable growth conditions in Dry and Intermediate zones used in the present study. Further, the identification of cyanobacteria in the present study was based on morphology, which may seriously undermine the true diversity. A similar study by Prasanna et al, 2009 in India has reported that rhizosphere soil samples collected at different rice growing areas were dominated by culturable heterocystous forms belonging to Anabaena and Nostoc, while other heterocystous forms Hapalosiphon, Westiellopsis and Calothrix and non-heterocystous forms, Oscillatoria and Phormidium occurred in the rhizosphere depending on the geographical locations and rice varieties. In addition, cyanobacterial phylotypes found in surface $(0-5 \mathrm{~cm})$ and sub-surface soils $(10-15 \mathrm{~cm})$ in rice fields have shown a seasonal variation with the crop growth (Song et al., 2005). They reported abundance of Leptolyngbya and Nostoc throughout the season and Synechococcus, Phormidium and Synechosystis, Scytonema, Cyanothece, Microcoleus, Chamaesiphon, Spirulina, and Chroococcidiopsis during different time periods using molecular methods. Thus the distribution and abundance of different cyanobacteria in paddy fields are found to be influenced by different ecohydrological factors such as soil properties, crop growth, water regime, type of fertilizers 
(Song et al., 2005) which determines the spatio-temporal variations in total bacterial and fungal community composition in paddy soils (Balasooriya et al., 2016).

In the studied rice fields, the most frequently found culturable cyanobacteria was Oscillatoria sp. Oscillatoria is inhabited by range of environmental factors including mild temperature $\left(26{ }^{\circ} \mathrm{C}\right)$ (e.g. Oscillatoria proboscides), high temperature $\left(38{ }^{\circ} \mathrm{C}\right)$ (e.g. Oscillatoria corntiana) and high dissolved oxygen level (e.g. O. corntiana) (Singh et al., 2014). Average temperatures in intermediate zone $\left(24-26^{\circ} \mathrm{C}\right)$ and dry zone $\left(28^{\circ} \mathrm{C}\right)$ fall within the favourable range for Oscillatoria. In addition, aerated conditions might have prevailed in surface layer of rice fields due to channel of atmospheric air through aerenchyma in the leaves, stems and roots of rice plants and aerated irrigation water. However, shaking of culture flasks might have influenced the abundance of Oscillatoria as well. In previous studies, Oscillatoria limosa (Stal and Krumbein, 1981), Oscillatoria sp. (Kumazawa and Mitsui, 1985), Oscillatoria sp. strains UCSB8 and UCSB 25 (Gallon et al., 1991) were reported as aerobic nitrogen fixing cyanobacteria in mariner environments. Although Oscillatoria are frequently found in terrestrial sites including paddy fields, studies on their $\mathrm{N}_{2}$ fixing potential are rare. Thus, evaluation of the isolated cyanobacteria for $\mathrm{N}_{2}$ fixation ability is prospected. Furthermore, cyanobacteria are known as sources of plant growth promoting substances such as, auxin (e.g. Anabaena and Nostoc) (Ahmad and Winter, 1968), cytokinin (e.g. Anabaena) (Rodgers et al., 1979) and gibberellins (e.g. Anabaenopsis) (Singh and Trehan, 1973). On the other hand, some cyanobacteria produce cyanotoxins, which include potent neurotoxins, hepatotoxins and cytotoxins (Bergman et al., 1997). Thus, it is essential to identify the cyanobacterial isolates using molecular techniques and then screen them for potential beneficial $\left(\mathrm{N}_{2}\right.$ fixation, $\mathrm{P}$ solubilisation, growth hormone production, etc.) and harmful characters (e.g. cyanotoxin production) prior to utilizing them as biofertilizers.

\section{CONCLUSIONS}

Thirteen cyanobacteria genera were isolated and tentatively identified from paddy soil crust in the intermediate and dry zones of Sri Lanka based on their morphological characteristics. Among them, 6 cyanobacteria genera were unicellular (Chroococcus, Aphanocapsa, Aphanothece, Synechococcus, Johannesbaptistia, Microsystis) and 7 genera were filamentous types (Lyngbya, Oscillatoria, Leptolyngbya, Pseudanabaena, Anabaena, Spirulina, Nostoc). Oscilatoria was the most abundant type among sampling sites in IL1, IM3, DL1b and DL1c agro ecological regions falling under Kurunegala, Matale, Anuradhapura and Polonnaruwa Districts. The prevalence of different types of cyanobacteria is higher in paddy fields in the Intermediate zone compared to Dry zone. Hence, the diversity of cyanobacteria is high in the regions with high diversity of paddy cultivated environments. Molecular analysis for further identification of cyanobacteria isolates is prospected.

\section{ACKNOWLEDGEMENT}

Authors acknowledge the funds received from the theme oriented research grant received by NRC (NRC TO 16-07) to conduct this research. 


\section{REFERENCES}

Ahmad, M.R. and Winter, A. (1968). Studies on the hormonal relationships of algae in pure culture: I. The effect of indole-3-acetic acid on the growth of blue-green and green algae. Planta. 78, 277-286.

Balasooriya, W.K., Huygens, D., Rajapaksha, R.M.C.P. and Boeckx, P. (2016). Effect of rice variety and fertilizer type on the active microbial community structure in tropical paddy fields in Sri Lanka. Geoderma, 265, 87-95.

Bergman, B., Gallon, J.R., Rai, A.N. and Stal, L.J. (1997). N N $_{2}$ fixation by mon-heterocystous cyanobacteria. FEMS Microbio. Rev. 19, 139-185.

Culman, S.W., Snapp, S.S., Freeman, M.A., Schipanski, M.E., Beniston, J., Lal, R., Drinkwater, L.E., Franzluebbers, A., Glover, J.D., Grandy, A.S., Lee, J., Six, J., Maul, J.E., Mirsky, S.B., Spargo, J.T. and Wander, M.M. (2012). Permanganate oxidizable carbon reflects a processed soil fraction that is sensitive to management. Soil Sci. Soc. Am. J. 76(2), 494-504.

Gallon, J.R., Hashem, M.A. and Chaplin, A.E. (1991). Nitrogen fixation by Oscillatoria spp. under autotrophic and photoheterotrophic conditions. J. Gen. Microbiolo. 137, 31-39.

Kaushik, B.D. (1994). Algalization of rice in salt-affected soils. Ann. Agric. Res. 14, $105-$ 106.

Kneip, C., Vob, C., Lockhart, P.J. and Maier, U.G. (2008). The cyanobacterial endosymbiont of the unicellular algae Rhopalodia gibba shows reductive genome evolution. BMC Evol. Biol. 8 (30), 1-16.

Kondo, M. and Yasuda, M. (2003). Seasonal changes in $\mathrm{N}_{2}$ fixation activity and $\mathrm{N}$ enrichment in paddy soils as affected by soil management in the northern area of Japan. Jpn. Agric. Res. Q. 37, 105-111.

Kulasooriya, S.A. (2011). Cyanobacteria: pioneers of planet earth. Ceylon J. Sci. Biol. Sci. 40 (2), 71-88.

Kulasooriya, S.A. and Magana-Arachci, D.N. (2016). A review: nitrogen fixing cyanobacteria: their diversity, ecology and utilization with special reference to rice cultivation. J. Natl. Sci. Found. Sri. 44 (2), 111-128.

Kumazawa, S. and Mitsui, A. (1985). Comparative amperometric study of uptake hydrogenase and hydrogen photo production activities between heterocystous cyanobacterium Anabaena cylindrica B699 and non-heterocystous cyanobacterium Oscillatoria sp. strain Miami BG7. Appl. Environ. Microbiol. 50, 287-291.

Lathiff, M.A. (2007a). Exchangeable cations (K, Ca and Mg). pp. 77-79. In: Dharmakeerthi, R.S., Indraratne, S.P. and Kumaragamage D. (Eds.), Manual of Soil Sampling and Analysis, Soil Science Society of Sri Lanka, Sri Lanka. 
Lathiff, M.A. (2007b). Electrical conductivity. pp. 51-53. In: Dharmakeerthi, R.S., Indraratne, S.P. and Kumaragamage, D. (Eds.) Manual of Soil Sampling and Analysis Soil Science Society of Sri Lanka.

Mapa, R.B., Somasiri, S. and Dasanayake, A.R. (2010). Soils of the dry zone of Sri Lanka. Special Publication 7, Soil Science Society of Sri Lanka, Sri Lanka. DOI: 10.13140/RG.2.2.24076.92808.

Mapa, R.B., Somasiri, S., Dasanayake, A.R. (Eds.) (2010). Soils of the Dry Zone of Sri Lanka. Special Publication No.7. Soil Science Society of Sri Lanka.

Mapa, S., Dasanayake, A.R. and Nayakekorale, H. B. (2005). Soils of the intermediate zone of Sri Lanka. Special Publication 4. Soil Science Society of Sri Lanka, Sri Lanka. DOI: 10.13140/RG.2.2.29529.52327

Mapa, S., Dasanayake, A.R., Nayakekorale, H.B. (Eds.) (2005). Soils of the Intermediate Zone of Sri Lanka. Special Publication No.4. Soil Science Society of Sri Lanka. Sri Lanka.

Meeks, J.C. (University of California, Davis) BG 11 medium [online]. [Accessed on 02 Feburay 2017]. Available at http:// microbiology. ucdavis.edu /meeks/BG11medium.html

Naveed, M., Mehboob, I., Shaker, M.A., Hussain M.B. and Farooq, M. (2015). Biofertilizers in Pakistan: Initiatives and limitations. Review Article. Int. J. Agric. Biol. 17(3), 411-420.

Naveed, M., Mehboob, I., Shaker, M.A., Hussain M.B. and Farooq, M. (2015). Biofertilizers in Pakistan: Initiatives and limitations. Review Article. Int. J. Agric. Biol. 17(3), 411-420

Prasanna, R., Jaiswal, P., Nayak, S., Sood, A. and Kaushik, B.D. (2009). Cyanobacterial diversity in the rhizosphere of rice and its ecological significance. Indian J. Microbiol. 49, 89-97.

Prasanna, R., Jaiswal, P., Nayak, S., Sood, A. and Kaushik, B.D. (2009). Cyanobacterial diversity in the rhizosphere of rice and its ecological significance. Indian J. Microbiol. 49, 89-97.

Rodgers, G.A., Bergman, B., Henriksson, E. and Udris, M. (1979). Utilization of blue-green algae as bio-fertilizers. Plant Soil. 52, 99-107.

Rodgers, G.A., Bergman, B., Henriksson, E. and Udris, M. (1979). Utilization of blue-green algae as bio-fertilizers. Plant Soil. 52, 99-107.

Roger, P.A. (1996). Biology and management of the flood water ecosystem in rice fields. International Rice Research Institute, Manila, Philippines.

Roger, P.A. (1996). Biology and management of the flood water ecosystem in rice fields. International Rice Research Institute, P. O. Box 933, Manila 1099, Philippines.

Saadatnia, H. and Riahi, H. (2009). Cyanobacteria from paddy fields in Iran as a bio fertilizer in rice plants. Plant Soil Environ. 55, 207-212. 
Saadatnia, H. and Riahi, H. (2009). Cyanobacteria from paddy fields in Iran as a bio fertilizer in rice plants. Plant Soil Environ. 55, 207-212.

Singh, J.S., Kumar, A., Rai, A.N. and Singh, D.P. (2016). Cyanobacteria: A precious bioresource in agriculture, ecosystem, and environmental sustainability. Front. Microbiol. 7, $1-19$.

Singh, J.S., Kumar, A., Rai, A.N., and Singh, D.P. (2016). Cyanobacteria: A Precious Bioresource in Agriculture, Ecosystem, and Environmental Sustainability. Front. Microbiol. 7(April), 1-19.

Singh, S.S., Kunui, K., Minj, R.A. and Singh, P. (2014). Diversity and distribution pattern analysis of cyanobacteria isolated from paddy fields of Chhattisgarh. India. J. Asia Pac. Biodivers. 7, 462-470.

Singh, S.S., Kunui, K., Minj, R.A. and Singh, P. (2014). Diversity and distribution pattern analysis of cyanobacteria isolated from paddy fields of Chhattisgarh, India. J. Asia Pac. Biodivers. 7, 462-470.

Singh, V.P. and Trehan, T. (1973). Effects of extracellular products of Aulosira fertilissuna on the growth of rice seedlings. Plant Soil, 38, 457-464.

Singh, V.P. and Trehan, T. (1973). Effects of extracellular products of Aulosira fertilissuna on the growth of rice seedlings. Plant Soil. 38, 457-464.

Song, T., Martensson, L., Eriksson, T., Zheng, W. and Rasmussen, U. (2005). Biodiversity and seasonal variation of the cyanobacterial assemblage in a rice paddy field in Fujian, China. FEMS Microbiol. Ecol. 54, 131-140.

Stal, L.J. and Krumbein, W.E. (1981). Aerobic nitrogen fixation in pure cultures of a benthic marine Oscillatoria (cyanobacteria). FEMS Microbiol. Lett. 11, 295-298.

Wanigatunge, R.P., Magana-Arachchi, D.N., Chandrasekharan, N.V. and Kulasooriya, S.A. (2014). Genetic diversity and molecular phylogeny of Cyanobacteria from Sri Lanka based on 16S rRNA gene. Environ. Eng. Res. 19 (4), 317-329.

Wehr, J.D. and Sheath, R.G. (2002). Freshwater Algae of North America, United States of America. Elsevier Science, New York City, New York, United States. 2, 196. 